\title{
Is dental anxiety associated with the behavior of sedated children?
}

\author{
Laércio Alves de AMORIM \\ JÚNIOR(a) \\ Vinícius Braudes Martins \\ RODRIGUES(a) iD \\ Luciane Rezende COSTA(b) \\ Patrícia CORRÊA-FARIA(c) \\ (a) Universidade Federal de Goiás - UFG, \\ School of Dentistry, Center for Studies in \\ Dental Sedation, Goiânia, GO, Brazil. \\ (b) Universidade Federal de Goiás - UFG, \\ School of Dentistry, Department of Oral \\ Health, Goiânia, GO, Brazil. \\ (c) Universidade Federal de Goiás - UFG, \\ School of Dentistry, Postgraduate Program \\ in Dentistry, Goiânia, GO, Brazil.
}

Abstract: The aim of this cross-sectional study was to investigate factors associated with dental anxiety in children treated under moderate sedation. Prior to treatment, each child's dental anxiety was evaluated using the modified Venham Picture Test (VPT). Interviews were also conducted with parents/guardians to gather information on the child's dental anxiety (Corah's Dental Anxiety Scale [DAS]), age and sex, shyness or anxiety in the presence of strangers, and dental history, as well as socioeconomic factors. All the children were sedated, and had at least one tooth restored using the atraumatic restorative treatment technique. Child behavior was assessed using the Frankl scale. Data analysis involved descriptive statistics and bivariate tests. The median VPT score was 2.0 (range: 0 to 8 ). Children who were shy in the presence of strangers (yes: median 2.0 [0-8]; no: 0.5 [0-4]; $p=0.018$ ), and those with negative behavior during dental care (negative: 3.0 [0-8]; positive: 1.0 [0-8]; $p=0.014$ ) had greater anxiety. The child's dental anxiety was associated with the mother's education level $(\leq 8$ years: 4 [2-7]; $>8$ years: 1 [0-8]; $\mathrm{p}=0.016$ ). The dental anxiety of children treated under sedation is associated with negative behavior, shyness, and the mother's education level.

Keywords: Dental Anxiety; Child, Preschool; Conscious Sedation; Child Behavior.

Declaration of Interests: The authors certify that they have no commercial or associative interest that represents a conflict of interest in connection with the manuscript.

Corresponding Author:

Patrícia Corrêa-Faria

E-mail: patriciafaria.faria09@gmail.com

hHtps://doi.org/10.1590/1807-3107bor-2021.vol35.0088

Submitted: June 29, 2020

Accepted for publication: February 9, 2021

Last revision: March 8, 2021

\section{Introduction}

Anxiety regarding dental treatment exerts a negative impact on both the child's comfort level, and the outcome of the dental procedure. Anxious children tend to anticipate dental care in an unrealistic way, ${ }^{1,2}$ This anticipation incites uncooperative behavior, ${ }^{3}$ which can make it difficult for the dentist to perform procedures. ${ }^{4,5}$ The prevalence of dental anxiety is 10 to $20 \%$ in children and adolescents. ${ }^{6}$ Given the negative implications of dental anxiety, it is important to identify anxious children, and associated factors, in order to provide adequate dental treatment planning.

Children's dental anxiety can be assessed by observing their behavior, by performing a psychometric evaluation using a questionnaire answered by the parent/guardian or child, and by analyzing physiological responses, such as altered salivary cortisol. ${ }^{6,7}$ A recent systematic review reports that dental anxiety in preschool children has been assessed by a proxy measure (mainly parental reports) in most studies published since $1998 .{ }^{6}$ 
Self-reports have been restricted to children older than six years of age, ${ }^{6}$ despite the existence of validated instruments for preschool children, such as the Facial Image Scale ${ }^{8}$ and the Venham Picture Test. ${ }^{9}$

The Venham Picture Test is one of the most widely recommended tools for assessing momentary anxiety toward dental treatment in children. The advantages of this instrument are its easy use, short application time, and properties such as adequate internal consistency and reliability. ${ }^{9}$ A modified version for use on Brazilian children was designed for the purpose of representing this population better. ${ }^{10}$ Despite these advantages, a search of PubMed (https:// www.ncbi.nlm.nih.gov/pubmed/) (December 2020) revealed that few studies have evaluated the anxiety of Brazilian children using this instrument. ${ }^{11-19} \mathrm{In}$ the studies cited, dental anxiety was assessed while using non-pharmacological behavior management techniques to compare the anxiety levels of children undergoing different procedure $\mathrm{s}^{13}$, or being submitted to different behavior management techniques. ${ }^{14,18}$ Other objectives were to monitor these levels in children with and without previous toothache experience over consecutive appointments, ${ }_{1}^{17}$ or to determine associated factors. ${ }^{16,19}$ None of these studies investigated dental anxiety in uncooperative children recommended for treatment under sedation.

The self-report is a good way to assess dental anxiety in pediatric dentistry. When only the perceptions of parents/guardians are considered, the complaints and anxiety of children may be underestimated. ${ }^{20} \mathrm{~A}$ lack of cooperation due to anxiety may be misconstrued as a behavioral problem, and could lead to the postponement of treatment, and consequential worsening of the oral condition. ${ }^{21}$ Therefore, the aims of the present study were to assess children's dental anxiety through child self-reports, and identify associated factors in uncooperative preschool children treated under sedation.

\section{Methodology}

This study received approval from the ethics committee of the Universidade Federal de Goiás (certificate number: 65277317.2.0000.5083). All parents/guardians received clarifications regarding the objectives and procedures of the study, and agreed to participate by signing a statement of informed consent. Informed assent was not obtained from the children, because they would probably resist accepting dental treatment, despite this entailing their participation in the study.

\section{Participants}

The participants of this cross-sectional study (convenience sample) - children and their parents/guardians - were selected between November 2017 and August 2019, among patients who presented for dental treatment under sedation at the School of Dentistry, Universidade Federal de Goiás, Brazil. All the children were between three and seven years of age. The center offers multidisciplinary dental care under sedation to children and adults with dental fear and/or anxiety. The team is comprised of general practitioners, pediatric dentists, anesthetists, pediatricians, and psychologists, as well as undergraduate and graduate students in the health field.

The inclusion criteria for the children were uncooperative behavior, needing restorative treatment on at least one tooth using an atraumatic restorative treatment technique, and a healthy physical status (classified as ASA I or ASA II). ${ }^{22}$ Among the requirements, the parent/guardian needed to live with the child most of the time. Children with chronic diseases, and those who had recently experienced stressful events, such as the death of a relative, were excluded.

\section{Procedures}

The child's behavior was evaluated during the clinical examination prior to dental treatment under sedation, at which time dental prophylaxis was applied using the Frankl behavior rating scale ${ }^{23}$. The procedures were performed by trained pediatric dentists, and the child's behavior was classified as definitely positive, positive, negative, or definitely negative. Negative behavior confirmed the need for sedation combined with non-pharmacological behavior management techniques. Caries experience was assessed using the $\mathrm{dmft}$ index. ${ }^{24}$

Self-reported dental anxiety was assessed using the modified Venham Picture Test (VPT).$^{10}$ This instrument comprises eight pairs of figures that reflect different 
emotions of children in a dental setting. The figures enable the child to distinguish sex and color/race (black or white), so that he/she can choose the option that best represents him/her. ${ }^{10}$ The instrument was applied by two trained dentists, without the interference of the child's parent/guardian, in the waiting room, prior to the procedure under sedation. The child was asked to point to the figure that best represented how he/she was feeling just before seeing the dentist. Each positive figure was assigned a zero score and each negative image was scored one point. The final score ranged from zero to eight.

In the same session, the parent/guardian was interviewed to collect data on the child (sex, age, shyness or anxiety in the presence of strangers), child's dental history (previous visits to a dentist and dental pain), and socioeconomic aspects, such as mother's education level in years, and monthly family income in reais. The amounts in reais were converted to commercial dollars using the amounts available in August 2019 ( $\$ 1$ US commercial dollar $=\$ 4.14$ Brazilian reais). The dental anxiety of the parents/guardians was assessed using Corah's Dental Anxiety Scale. ${ }^{25}$ This scale is comprised of four questions, each with five response options. The final score ranges from 1 to 20 points, and is used to categorize dental anxiety as: slightly anxious ( $<5$ points), mildly anxious ( 6 to 10 points), moderately anxious (11 to 15 points), or extremely anxious (16 to 20 points).

After the collection of non-clinical data, the children were sedated by an anesthesiologist using dexmedetomidine with or without ketamine (at his discretion). Vital signs (heart rate and oxygen saturation) were continuously monitored by an observer using a pulse oximeter. The AAP/AAPD guidelines ${ }^{26}$ for safe dental sedation were followed. Decayed teeth were restored by one of five pediatric dentists who had experience in sedation care, and who had been trained prior to data collection to perform the procedure using the atraumatic restorative treatment technique. The training was divided into two stages, theoretical and practical (using extracted teeth).

During the consultation, the pediatric dentist in charge treated as many teeth as possible, while the child was still cooperative to the dental treatment. As soon as the dentist noticed that the sedative effect was wearing off (child awakening or becoming agitated), the procedure in progress was completed, and the consultation was ended. The duration of the consultation was not standardized, since the time of sedative action varied among the children. At the end of the treatment, the pediatric dentist (Kendall's coefficient of concordance: 0.810 ) evaluated the child's behavior using the Frankl scale criteria. ${ }^{23}$

\section{Statistical analysis}

The data were analyzed using the Statistical Package for the Social Sciences, version 25.0 (SPSS, Chicago, USA). After the descriptive analysis, bivariate tests were performed to determine associations between the dependent variable (child anxiety) and independent variables related to the child (sex, age, shyness or anxiety in the presence of strangers), family (mother's education level [cut-off point of eight years], parents'/guardians' dental anxiety, and monthly family income in reais) and oral health (dental pain, previous visits to dentist, behavior during dental treatment under sedation, and dental caries experience). The Mann-Whitney and Kruskal-Wallis tests were used to compare the child's dental anxiety score among the categories of qualitative variables. The linear relationship among the numerical variables was determined using Spearman's correlation test. The significance level for all the tests was set at $5 \%$.

\section{Results}

During the data collection period, 88 children aged between 2 and 7 years were seen to. Of this total, 44 children from 3 to 7 years old $(56.8 \%$ male; mean age: 4.2 years, standard deviation $=1.05$ ) and respective parents/guardians (75.5\% mothers) participated in the study. The median VPT score was 2.0 (range: 0 to 8 ). Most children behaved positively $(\mathrm{n}=24 ; 55.8 \%)$ during dental treatment under sedation. The characteristics of the children and their families are shown in Table 1.

The children's anxiety was not correlated with age $($ rho $=-0.110 ; p=0.476)$, caries experience $(r h o=0.118$; $\mathrm{p}=0.446$ ), or monthly household income ( $\mathrm{rho}=-0.060$; $\mathrm{p}=0.699)$. The VPT score did not differ significantly between the different categories of sex $(p=0.546)$, dental 
Table 1. Characteristics of participants $(n=44)$.

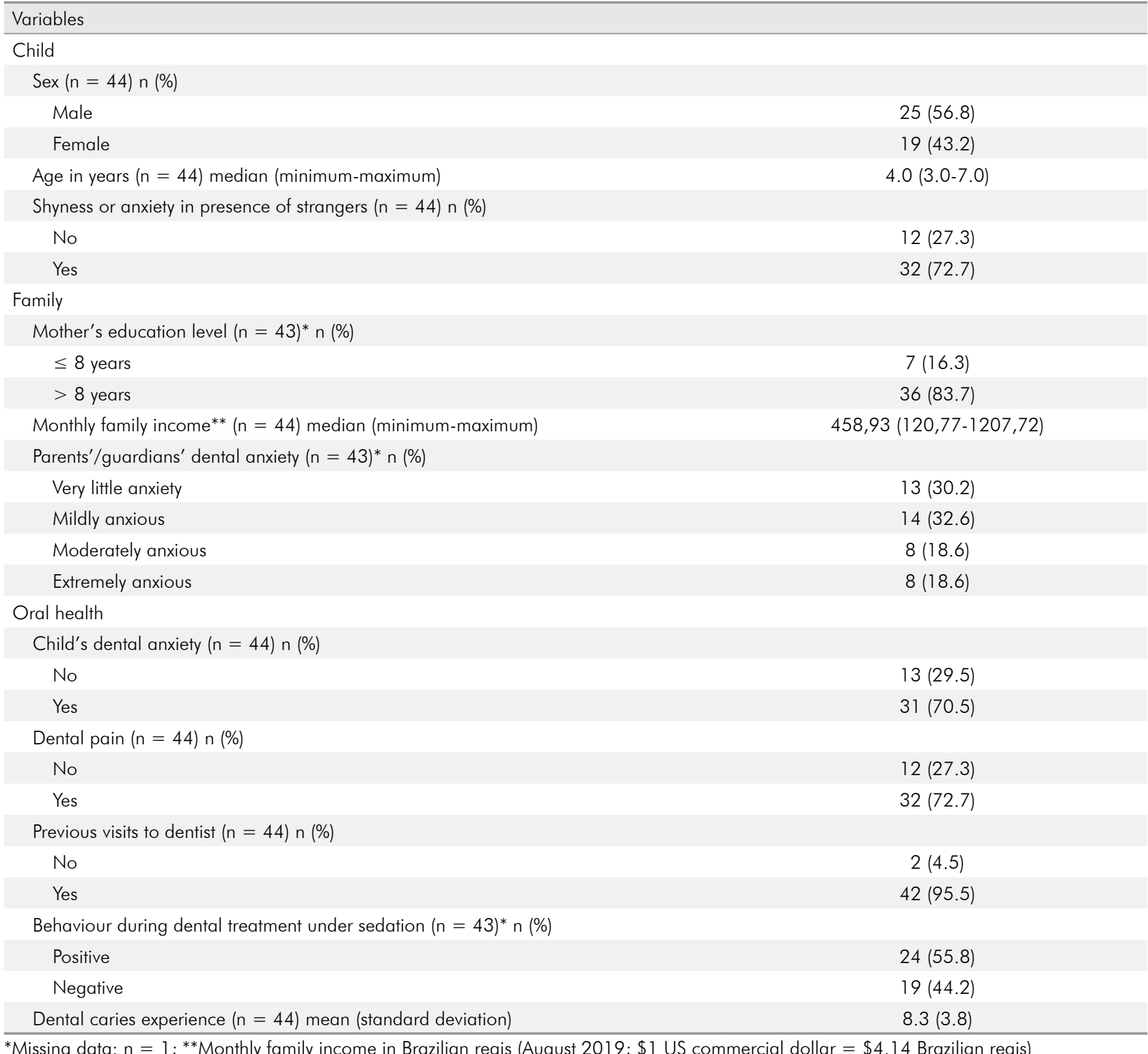

*Missing data: $\mathrm{n}=1 ;{ }^{* *}$ Monthly family income in Brazilian reais (August 2019; $\$ 1$ US commercial dollar $=\$ 4.14$ Brazilian reais)

pain $(p=0.107)$, or previous visits to a dentist $(p=0.239)$. Higher levels of anxiety were found among children who were shy/anxious in the presence of strangers $(p=0.018)$, those with negative behavior during care under sedation $(p=0.014)$, and those whose mothers had a lower education level $(p=0.016)$ (Table 2$)$.

\section{Discussion}

In this study, dental anxiety among the children (VPT $\geq 1$ ) was highly frequent, and was found in children with negative behavior during care under sedation, in those reported to be shy/anxious in the presence of strangers, and in those whose mothers had a lower educational level.

The association between dental anxiety and negative behavior corroborates the findings described in previous studies. ${ }^{27,28,29}$ In the present investigation, the children had a history of negative behavior, which kept the dentists from performing dental procedures in previous appointments. Indeed, dental anxiety is one of the factors considered in indicating dental sedation. ${ }^{30}$ 
Table 2. Comparison punctuation of VPT among categories of independent variables.

\begin{tabular}{|c|c|c|}
\hline \multirow{2}{*}{ Variables } & Child's dental anxiety & \multirow{2}{*}{$\mathrm{p}$-value } \\
\hline & Median (minimum-maximum) & \\
\hline \multicolumn{3}{|l|}{ Child } \\
\hline Sex n (\%) & & $0.230^{\circ}$ \\
\hline Male & $1.0(0.0-8.0)$ & \\
\hline Female & $2.0(0.0-8.0)$ & \\
\hline Shyness or anxiety in presence of strangers $n(\%)$ & & $0.018^{a}$ \\
\hline No & $0.5(0.0-4.0)$ & \\
\hline Yes & $2.0(0.0-8.0)$ & \\
\hline \multicolumn{3}{|l|}{ Family } \\
\hline Mother's education level $n$ (\%) & & $0.016^{a}$ \\
\hline$\leq 8$ years & $4.0(2.0-7.0)$ & \\
\hline$>8$ years & $1.0(0.0-8.0)$ & \\
\hline Parents/guardian' dental anxiety n (\%) & & $0.509^{b}$ \\
\hline Very little anxiety & $1.0(0.0-8.0)$ & \\
\hline Mildly anxious & $2.0(0.0-8.0)$ & \\
\hline Moderately anxious & $1.5(0.0-8.0)$ & \\
\hline Extremely anxious & $2.5(1.0-4.0)$ & \\
\hline \multicolumn{3}{|l|}{ Oral health } \\
\hline Dental pain $(n=44) n(\%)$ & & $0.107^{\circ}$ \\
\hline No & $3.0(0.0-7.0)$ & \\
\hline Yes & $1.0(0.0-8.0)$ & \\
\hline Previous visits n (\%) & & $0.239^{a}$ \\
\hline No & $4.0(3.0-5.0)$ & \\
\hline Yes & $1.5(0.0-8.0)$ & \\
\hline Behaviour during dental treatment under sedation $\mathrm{n}(\%)$ & & $0.014^{\mathrm{a}}$ \\
\hline Positive & $1.0(0.0-8.0)$ & \\
\hline Negative & $3.0(0.0-8.0)$ & \\
\hline
\end{tabular}

A high percentage of children (44.2\%) exhibited negative behavior while receiving dental care under sedation, and this behavior was associated with higher levels of dental anxiety. To the best of our knowledge, this is the first study to research the association between self-reported dental anxiety and the child's behavior during treatment under sedation. The association between anxiety and negative behavior should be investigated further in studies involving a larger number of participants, to determine a reliable cut-off point for identifying anxious children with positive behavior who would benefit from sedation, and those with negative behavior who should receive general anesthesia.

Shy children were more anxious than those who did not feel shy in the presence of strangers. This result corroborates the findings described in a study involving Indian children three to six years of age, in which a significant positive correlation was found between shyness and childhood anxiety at the first dental appointment. ${ }^{31}$ The association between shyness and anxious behavior was also noteworthy (data not shown) ${ }^{31}$ These associations can help pediatric dentists predict a child's behavior, and select management techniques to reduce the child's anxiety, and make the care experience more comfortable.

Most parents/guardians felt very little or mild anxiety. A similar finding was described in a previous study involving parents of Brazilian preschool children ${ }^{16}$. In the present study, the low anxiety on the part of parents/guardians may be related to the clarifications given to the participants prior to 
sedation. ${ }^{31}$ Furthermore, eye contact between the dental team and the parents/guardians enabled greater interaction and trust, thus promoting a consequential reduction in anxiety. ${ }^{32,33}$

A higher VPT score was found in children whose mothers had a lower level of education (less than eight years of study). These mothers likely had lower oral health literacy (OHL), ${ }^{34}$ had a poor understanding of health information, and were less able to adopt a positive behavior toward their child's health..$^{35}$ Poor OHL may also exert a negative effect on the patient-dentist relationship, and on views toward dental care. Thus, mothers can transfer their negative experiences to children, who become anxious during dental care. However, this result should be interpreted with caution, since OHL was not evaluated in the present investigation. Further studies are needed to examine the association between family characteristics and childhood anxiety.

Variables related to oral health (previous visits to a dentist, dental pain, and caries experience) were not associated with the children's dental anxiety. Most children shared similar dental histories, such as uncooperative behavior during a previous visit, need for extensive treatment, and dental pain. This could explain the lack of difference in the levels of dental anxiety between categories of oral health variables.

Dental anxiety was self-reported by the children in the waiting room, using the modified version of the VPT, which has been validated for use on Brazilian children, and which is easy to use and understand. ${ }^{10}$ The self-report enables the dental team to understand anxiety from the patient's point of view, thus reducing the risk of underestimation inherent in the proxy measure..$^{20}$ Despite these advantages, we believe that there may have been an overestimation of anxiety in the children. When the children were scheduled for treatment under sedation, parents/guardians were advised that fasting was required. ${ }^{26}$ Fasting, coupled with waiting for dental treatment on the day of sedation, can cause greater discomfort, leading to an overestimation of anxiety. In an effort to minimize this limitation, the dental team tried to limit the waiting time of these children as much as possible.

The cross-sectional design of the study does not enable the establishment of causal relations to be established between dental anxiety and associated factors. Moreover, the small number of participants limited the generalization of results. Nevertheless, despite these limitations, this study has several strengths, including the care delivered to the children by pediatric dentists experienced with treatment under sedation, and the use of a minimally invasive technique (atraumatic restorative treatment) to restore the decayed teeth. These measures benefited the children by making the treatment care more comfortable.

All in all, we understand that these findings add to the literature on the management of children's behavior in the dental setting, by emphasizing the relevance of listening to the voice of children manifesting their dental anxiety. Further studies researching sedated and non-sedated children should be performed to assess to what extent the young children's self-reported dental anxiety can help in choosing the most appropriate combination of behavior management techniques for this special population.

\section{Conclusion}

In conclusion, the present results reveal associations between self-reported dental anxiety just before the procedure and children's shyness with strangers, and in regard to negative behavior during dental sedation care. These findings underscore the importance of identifying potentially anxious children, and proposing measures to reduce anxiety by combining non-pharmacological and pharmacological techniques to manage child behavior.

\section{References}

1. Klingberg G, Broberg AG. Dental fear/anxiety and dental behaviour management problems in children and adolescents:

a review of prevalence and concomitant psychological factors. Int J Paediatr Dent. 2007 Nov;17(6):391-406.

https://doi.org/10.1111/j.1365-263X.2007.00872.x 
2. AsI AN, Shokravi M, Jamali Z, Shirazi S. Barriers and drawbacks of the assessment of dental fear, dental anxiety and dental phobia in children: a critical literature review. J Clin Pediatr Dent. 2017;41(6):399-423. https://doi.org/10.17796/1053-4628-41.6.1

3. Kothari S, Gurunathan D. Factors influencing anxiety levels in children undergoing dental treatment in an undergraduate clinic. J Family Med Prim Care. 2019 Jun;8(6):2036-41. https://doi.org/10.4103/jfmpc.jfmpc_229_19

4. Cohen SM, Fiske J, Newton JT. The impact of dental anxiety on daily living. Br Dent J. 2000 Oct;189(7):385-90. https://doi.org/10.1038/sj.bdi.4800777

5. Yuwannisa M, Runkat J, Indrivanti R. Dental anxiety level of children patient during dental treatment using CFSS-DS questionnaire. Padjadjaran J Dent. 2013;25(1):1-9. https://doi.org/10.24198/pjd.vol25nol.15571

6. Cianetti S, Lombardo G, Lupatelli E, Pagano S, Abraha I, Montedori A, et al. Dental fear/anxiety among children and adolescents. A systematic review. Eur J Paediatr Dent. 2017 Jun;18(2):121-30. https://doi.org/10.23804/eipd.2017.18.02.07

7. Porritt J, Buchanan H, Hall M, Gilchrist F, Marshman Z. Assessing children's dental anxiety: a systematic review of current measures. Community Dent Oral Epidemiol. 2013;41(2);130-142. https://doi.org/10.1111/j.1600-0528.2012.00740.x

8. Buchanan H, Niven N. Validation of a Facial Image Scale to assess child dental anxiety. Int J Paediatr Dent. 12(1):47-52. https://doi.org/10.1046/i.0960-7439.2001.00322.x

9. Venham LL, Gaulin-Kremer E. A self-report measure of situational anxiety for young children. Pediatr Dent. 1979 Jun;1(2):91-6.

10. Ramos-Jorge ML, Pordeus IA. Por que e como medir a ansiedade infantil no ambiente odontológico: apresentação do teste VPT modificado. JBP Rev Ibero-Am Odontopediatr Odontol Bebê. 2004;7(37):282-90.

11. Smolarek PC, Silva LS, Martins PR, Hartman KD, Bortoluzzi MC, Chibinski AC. Evaluation of pain, disruptive behaviour and anxiety in children aging 5-8 years old undergoing different modalities of local anaesthetic injection for dental treatment: a randomised clinical trial. Acta Odontol Scand. 2020 Aug;78(6):445-53. https://doi.org/10.1080/00016357.2020.1757752

12. Cademartori MG, Cara G, Pinto GD, Costa VP. Validity of the Brazilian version of the Dental Subscale of Children's Fear Survey Schedule. Int J Paediatr Dent. 2019 Nov;29(6):736-47. https://doi.org/10.1111/ipd.12543

13. Soares JP, Cardoso M, Bolan M. Demystifying behaviour and dental anxiety in schoolchildren during endodontic treatment for primary teeth-controlled clinical trial. Int J Paediatr Dent. 2019 May;29(3):249-56. https://doi.org/10.1111/ipd.12468

14. Rank RC, Vilela JE, Rank MS, Ogawa WN, Imparato JC. Effect of awards after dental care in children's motivation. Eur Arch Paediatr Dent. 2019 Apr;20(2):85-93. https://doi.org/10.1007/s40368-018-0394-0

15. Huamani JRS, Barbosa TS, Freitas CN, Sousa KG, Gavião MB, Leal SC, et al. Assessment of anxiety and stress markers in children submitted to educational strategies and ART-restoration: A randomized clinical trial. Arch Oral Biol. 2019 Jan;97:191-7. https://doi.org/10.1016/i.archoralbio.2018.10.032

16. Busato P, Garbín RR, Santos CN, Paranhos LR, Rigo L. Influence of maternal anxiety on child anxiety during dental care: cross-sectional study. Sao Paulo Med J. 2017 Mar-Apr;135(2):116-22. https://doi.org/10.1590/1516-3180.2016.027728102016

17. Ramos-Jorge J, Marques LS, Homem MA, Paiva SM, Ferreira MC, Oliveira Ferreira F, et al. Degree of dental anxiety in children with and without toothache: prospective assessment. Int J Paediatr Dent. 2013 Mar;23(2):125-30. https://doi.org/10.1111/j.1365-263X.2012.01234.x

18. Ramos-Jorge ML, Ramos-Jorge J, Vieira de Andrade RG, Marques LS. Impact of exposure to positive images on dental anxiety among children: a controlled trial. Eur Arch Paediatr Dent. 2011 Aug;12(4):195-9. https://doi.org/10.1007/BF03262806

19. Ramos-Jorge ML, Marques LS, Pavia SM, Serra-Negra JM, Pordeus IA. Predictive factors for child behaviour in the dental environment. Eur Arch Paediatr Dent. 2006 Dec;7(4):253-7. https://doi.org/10.1007/BF03262561

20. Silva AN, Mendonça MH, Vettore MV. The association between low-socioeconomic status mother's Sense of Coherence and their child's utilization of dental care. Community Dent Oral Epidemiol. 2011 Apr;39(2):115-26. https://doi.org/10.1111/j.1600-0528.2010.00576.x

21. Klaassen MA, Veerkamp JS, Hoogstraten J. Young children's Oral Health-Related Quality of Life and dental fear after treatment under general anaesthesia: a randomized controlled trial. Eur J Oral Sci. 2009 Jun;117(3):273-8. https://doi.org/10.1111/j.1600-0722.2009.00627.x

22. Mayhew D, Mendonça V, Murthy BV. A review of ASA physical status - historical perspectives and modern developments. Anaesthesia. 2019 Mar;74(3):373-9. https://doi.org/10.1111/anae.14569

23. Frankl S, Shiere F, Fogels H. Should the parent remain with the child in the dental operatory. ASDC J Dent Child. 1962;29:150-63.

24. World Health Organization. Oral health surveys: basic methods. 4th ed. Geneva: World Health Organization; 1997 [cited 2020 Jun 29 ]. Available from https://apps.who.int/iris/handle/10665/41905

25. Freeman RE. Dental anxiety: a multifactorial aetiology. Br Dent J. 1985;159(12):406-408. https://doi.org/10.1038/sj.bdj.4805743

26. Coté CJ, Wilson S. Guidelines for monitoring and management of pediatric patients before during, and after sedation for diagnostic and therapeutic procedures. Pediatrics. 2019 Jun;143(6):e20191000. https://doi.org/10.1542/peds.2019-1000

27. Colares V, Richman L. Factors associated with uncooperative behavior by Brazilian preschool children in the dental office. ASDC J Dent Child. 2002 Jan-Apr;69(1):87-91.

28. Mathur J, Diwanii A, Sarvaiya B, Sharma D. Identifying dental anxiety in children's drawings and correlating it with Frankl's Behavior Rating Scale. Int J Clin Pediatr Dent. 2017 Jan-Mar;10(1):24-8. https://doi.org/10.5005/ip-journals-10005-1401 
Is dental anxiety associated with the behavior of sedated children?

29. Jamali Z, Vatandoost M, Erfanparast L, Aminabadi NA, Shirazi S. The relationship between children's media habits and their anxiety and behaviour during dental treatment. Acta Odontol Scand. 2018 Apr;76(3):161-8. https://doi.org/10.1080/00016357.2017.1396493

30. American Academy of Pediatric Dentistry. Behavior guidance for the pediatric dental patient. Pediatr Dent. 2017 Sep;39(6):246-59.

31. Jain A, Suprabha BS, Shenoy R, Rao A. Association of temperament with dental anxiety and behaviour of the preschool child during the initial dental visit. Eur J Oral Sci. 2019 Apr;127(2):147-55. https://doi.org/10.1111/eos.12606

32. Luk CY, Fu E, Mathu-Muju KR. The effect of an audiovisual preoperative intervention in reducing parental anxiety prior to a child's sedation appointment: a pilot study. Pediatr Dent. 2019 Mar;41(2):112-8.

33. Sandberg EH, Sharma R, Sandberg WS. Deficits in retention for verbally presented medical information. Anesthesiology. 2012 Oct;117(4):772-9. https://doi.org/10.1097/ALN.0b013e31826a4b02

34. Sun X, Chen J, Shi Y, Zeng Q, Wei N, Xie R, et al. Measuring health literacy regarding infectious respiratory diseases: a new skills-based instrument. PLoS One. 2013 May;8(5):e64153. https://doi.org/10.1371/journal.pone.0064153

35. Richman JA, Huebner CE, Leggott PJ, Mouradian WE, Mand LA. Beyond word recognition: understanding pediatric oral health literacy. Pediatr Dent. 2011 Sep-Oct;33(5):420-5. 